\title{
Jaringan Saraf Tiruan dengan Backpropagation untuk Memprediksi Penyakit Asma
}

\author{
Dahriani Hakim Tanjung \\ STMIK Potensi Utama Medan \\ E-mail: notashapire@gmail.com
}

\begin{abstract}
Abstrak
Penelitian ini bertujuan untuk memprediksi penyakit asma menggunakan teknik pengenalan pola yaitu jaringan saraf tiruan dengan metode backpropagation. Data penilaian asma mengacu pada riwayat penyakit asma seseorang. Jaringan saraf tiruan dilakukan dengan menentukan jumlah unit untuk setiap lapisan dengan fungsi aktivasi sigmoid biner. Pengujian dilakukan menggunakan perangkat lunak matlab yang diuji dengan beberapa bentuk arsitektur jaringan. Arsitektur dengan konfigurasi terbaik terdiri dari 18 lapisan masukan, 8 lapisan tersembunyi dan 4 lapisan keluaran dengan nilai learning rate sebesar 0.5, nilai toleransi error 0.001, menghasilkan maksimal epoch 4707 dan MSE 0.00100139. MSE berada di bawah nilai error yaitu 0.001, Parameter tersebut dipilih menjadi parameter terbaik karena menghasilkan jumlah iterasi yang memiliki nilai akurasi MSE yang cukup baik, karena nilai MSE paling kecil dari arsitektur yang lain serta nilai MSE dibawah dari nilai error yang ditentukan. Sigmoid Biner Fungsi ini digunakan untuk jaringan saraf yang dilatih dengan menggunakan metode backpropagation. Fungsi sigmoid memiliki nilai range 0 sampai 1. Oleh karena itu, fungsi ini sering digunakan untuk jaringan saraf yang membutuhkan nilai output yang terletak pada interval 0 sampai 1 .
\end{abstract}

Kata Kunci — Jaringan Saraf Tiruan, Backpropagation, Sigmoid biner, Matlab, MSE

\begin{abstract}
This study aims to predict asthma using pattern recognition techniques namely artificial neural network with back propagation method. Asthma assessment data refers to a person's history of asthma. Artificial neural network is done by determining the number of units for each layer with binary sigmoid activation function. Testing is done using matlab software being tested with some form of network architecture. Architecture with the best configuration consists of 18 layers of input, 8 hidden layer and output layer 4 with a value of learning rate of 0.5, the error tolerance value 0001, 4707 and resulted in the maximum epoch MSE .00100139. MSE is under the error value is 0.001, the parameter is chosen to be the best parameters for generating the number of iterations that have an accuracy value of MSE is quite good, because the smallest MSE value than other architectures as well as the value of the MSE under a specified error value. Binary sigmoid function is used for neural network trained using the backpropagation method. Sigmoid function has a value in the range 0 to 1 . Therefore, this function is often used for neural networks that require output value lies in the interval 0 to 1.
\end{abstract}

Keywords - Neural Networks, Backpropagation, Sigmoid binary, Matlab, MSE 


\section{PENDAHULUAN}

Asma merupakan masalah kesehatan global yang serius. Penyakit ini dapat menyerang semua orang dari segala usia di seluruh dunia. Asma adalah gangguan peradangan saluran pernapasan kronis di mana banyak sel dan elemen - elemen seluler yang seperti sel mast, eosinophil, limfosit $\mathrm{T}$, neutrophil dan sel epitel yang dapat menyebabkan inflamasi.

Serangan asma yang berat dapat menyebabkan kematian Faktor-faktor utama penyebab kematian karena asma adalah ketidaktepatan diagnosis, penelitian beratnya asma oleh penderita maupun oleh dokter yang merawat kurang akurat, serta pengobatan yang kurang memadai. Oleh karena itu, ketepatan dalam diagnosis, penilaian beratnya asma, serta pemberian pengobatan yang tepat merupakan kunci pengobatan dalam serangan asma akut.

Adapun metode problem solving yang digunakan dalam penelitian ini adalah jaringan syaraf tiruan (JST). Jaringan syaraf tiruan telah banyak digunakan untuk membantu menyelesaikan berbagai macam permasalahan, salah satu permasalahan tersebut adalah pencocokan/keakurasian berdasarkan pelatihan yang diberikan. Misalnya dalam bidang kesehatan, JST dapat dimanfaatkan untuk memprediksi penyakit asma dengan menggunakan metode Backpropagation.

\section{METODE PENELITIAN}

\subsection{Jaringan Saraf Tiruan}

Jaringan Saraf Tiruan (arficial neural network) atau di singkat JST adalah sistem komputasi dengan arsitektur dan operasinya diilhami dari pengetahuan tentang sel saraf biologi di dalam otak. JST dapat digambarkan sebagai model matematis dan komputasi untuk fungsi aproksimasi nonlinear, klasifikasi data, cluster dan regresi non parametric atau sebagai sebuah simulasi dari koleksi model saraf biologi[1].

\subsubsection{Fungsi Aktivasi Sigmoid Biner}

Fungsi ini digunakan untuk jaringan saraf yang dilatih dengan menggunakan metode backpropagation. Fungsi sigmoid memiliki nilai pada range 0 sampai 1 . Oleh karena itu, fungsi ini sering digunakan untuk jaringan saraf yang membutuhkan nilai output yang terletak pada interval 0 sampai 1 . Namun, fungsi ini bisa juga digunakan oleh jaringan saraf yang nilai outputnya 0 atau $1[2]$

Fungsi sigmoid dirumuskan sebagai berikut:

$$
y=f(x)=\frac{1}{1+\exp (-\sigma x)}
$$

Fungsi Step dirumuskan sebagai:

$$
\text { dengan: } y^{\prime}(x)=\sigma f(x)[1-f(x)]
$$

\subsubsection{Metode Backpropagation}

Backpropagation merupakan algoritma pembelajaran yang terawasi dan baisanya digunakan oleh perceptron dengan banyak lapisan untuk mengubah bobot-bobot yang berhubungan dengan neuron-neuron yang ada pada lapisan tersembunyinya. Algoritma backpropagation menggunakan error output untuk mengubah nilai bobot-bobotnya dalam arah mundur (backward). Untuk mendapatkan error ini, tahap perambatan maju (forward propagation) harus dikerjakan terlebih dahulu. 
Pada dasarnya, pelatihan dengan metode backpropagtion terdiri atas tiga langkah, yaitu sebagai berikut:

a. Data dimasukkan ke input jaringan (feedforward)

b. Perhitungan dan propagasi balik dari error yang bersangkutan

c. Pembaharuan (adjustment) bobot dan bias.

\subsubsection{Arsitektur Jaringan Metode Backpropagation}

Jaringan saraf terdiri dari 3 lapisan, yaitu lapisan masukan/input terdiri atas variable masukan unit sel saraf, lapisan tersembunyi terdiri atas 10 unit sel saraf, dan lapisan keluaran/output terdiri atas 4 sel saraf. Lapisan masukan digunakan untuk menampung 18 variabel yaitu X1 sampai dengan X18, sedangkan 4 lapisan keluaran digunakan untuk mempresentasikan pengelompokan pola, nilai 0001 untuk Asma Akut Persisten Ringan, nilai 0010 untuk Asma Akut Persisten Sedang, nilai 0100 untuk Asma Akut Persisten Berat, dan nilai 1000 untuk Asma Akut Mengancam Jiwa[3].

\subsubsection{Inisialisasi Input}

Pada tahap ini dilakukan proses inisialisasi data input yang diperoleh dari gejalagejala/kriteria penilaian yang telah diperiksa oleh dokter spesialis penyakit paru untuk menentukan hasil penilaian penyakit asma. Kriteria-kriteria penilaian penyakit asma secara umum mencakup keadaan dan kondisi pasien yang diuraikan secara lebih rinci agar dapat dinilai sesuai dengan kenyataan sebenarnya. Nilai terhadap variable ditentuka Antara 0 sampai 1 disesuaikan dengan kasus dari masing gejala.

Tabel 1. Kriteria Dan Inisialisasi Penyakit Asma

\begin{tabular}{|l|l|l|}
\hline No & Kriteria Yang Dinilai & Inisialisasi \\
\hline 1 & Aktivitas relatif normal & $\mathrm{X} 1$ \\
\hline 2 & Berbicara satu kalimat dalam satu napas & $\mathrm{X} 2$ \\
\hline 3 & Nadi $<100$ & $\mathrm{X} 3$ \\
\hline 4 & APE $>80 \%$ & $\mathrm{X} 4$ \\
\hline 5 & Berjalan jauh menimbulkan gejala & $\mathrm{X} 5$ \\
\hline 6 & Berbicara beberapa kata dalam satu napas & $\mathrm{X} 6$ \\
\hline 7 & Nadi $100-120$ & $\mathrm{X} 7$ \\
\hline 8 & APE $60-80 \%$ & $\mathrm{X} 8$ \\
\hline 9 & Sesak Saat istirahat & $\mathrm{X} 9$ \\
\hline 10 & Berbicara kata perkata dalam satu napas & $\mathrm{X} 10$ \\
\hline 11 & Nadi $>120$ & $\mathrm{X} 11$ \\
\hline 12 & APE $<60 \%$ atau 100 1/dtk & $\mathrm{X} 12$ \\
\hline 13 & Kesadaran berubah/ menurun & $\mathrm{X} 13$ \\
\hline 14 & Gelisah & $\mathrm{X} 14$ \\
\hline 15 & Sianosis & $\mathrm{X} 15$ \\
\hline 16 & Gagal Napas & $\mathrm{X} 16$ \\
\hline 17 & Batuk & $\mathrm{X} 17$ \\
\hline 18 & Nyeri Ulu Hati & $\mathrm{X} 18$ \\
\hline
\end{tabular}


Citec Journal, Vol. 2, No. 1, November 2014 - Januari 2015

\subsubsection{Inisialisasi Output}

Hasil yang diiinginkan pada tahap ini adalah terdeteksinya suatu nilai untuk memprediksi penyakit asma. Tabel 2 berikut adalah nilai target keluaran.

Tabel 2. Prediksi dan Inisialisasi Penyakit Asma

\begin{tabular}{|c|l|c|}
\hline No & \multicolumn{1}{|c|}{ Prediksi Penyakit Asma } & Inisialisasi \\
\hline 1 & Asma Akut Persisten Ringan & 0001 \\
\hline 2 & Asma Akut Persisten Sedang & 0010 \\
\hline 3 & Asma Akut Persisten Berat & 0100 \\
\hline 4 & Asma Akut Mengancam Jiwa & 1000 \\
\hline
\end{tabular}

\subsubsection{Arsitektur Jaringan Saraf Tiruan}

Arsitektur sebuah jaringan akan menentukan keberhasilan target yang akan dicapai karena tidak semua permasalahn dapat diselesaikan dengan arsitektur yang sama. Arsitektur jaringan yang akan digunakan untuk memprediksi penyakit asma mengunakan banyak lapisan (multilayer net). Model ini merupakan jaringan dengan banyak lapisan yang memiliki satu atau lebih lapisan yang terletak di antara lapisan input dan lapisan output. Lapisan input terdiri dari 18 simpul yang disimpan dalam variabel X1 sampai dengan X18. Lapisan tersembunyi ditentukan sendiri oleh pengguna sistem melalui cara percobaan konvergensi terbaik (trial and error) sampai diperoleh hasil konvergensi pelatihan yang paling baik (jumlah epoch terkecil). Sedangkan lapisan output terdiri dari 4 simpul yaitu asma akut persisten ringan, asma akut persisten sedang, asma akut persisten berat dan asma akut mengancam jiwa. Gambar 2 merupakan arsitektur jaringan saraf tiruan.

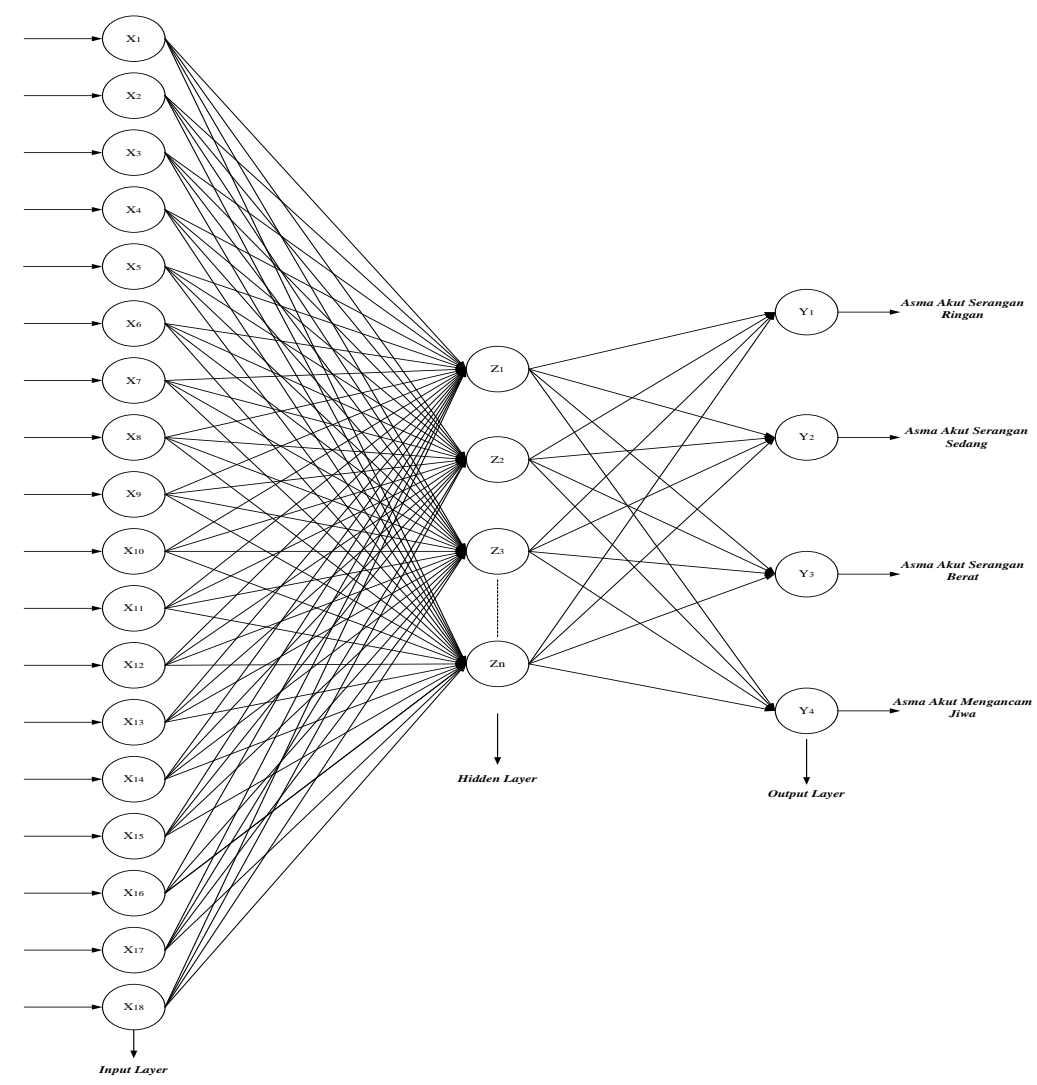

Gambar 1. Arsitektur Jaringan Untuk Memprediksi Penyakit Asma 


\subsection{Mean Square Error}

Dalam arti, setiap ukuran pusat distribusi harus dikaitkan dengan beberapa ukuran kesalahan. Jika kita mengatakan bahwa jumlah t adalah ukuran yang baik dari pusat, maka mungkin kita katakan $\mathrm{t}$ yang mewakili seluruh distribusi yang lebih baik, dalam beberapa cara, dari nomor lain. Dalam konteks ini, misalkan kita mengukur kualitas t, sebagai ukuran pusat distribusi, dalam hal mean square error.

$$
\operatorname{MSE}(t)=\frac{1}{n} \sum_{i=1}^{k} f i\left(x_{i}-t\right)^{2}=\sum_{i=1}^{k} p_{i}\left(x_{i}-t\right)^{2}
$$

1. MSE (t) adalah rata-rata tertimbang dari kuadrat jarak antara $t$ dan tanda kelas dengan frekuensi relatif sebagai faktor berat badan. Dengan demikian, ukuran terbaik dari pusat, relatif terhadap ukuran kesalahan, adalah nilai t yang meminimalkan MSE.Perhatikan bahwa MSE adalah fungsi kuadrat dari t. Dengan demikian, berpendapat bahwa grafik MSE adalah parabola membuka ke atas.

2. Gunakan kalkulus standar untuk menunjukkan bahwa varians tersebut adalah nilai minimum MSE dan nilai minimum ini terjadi hanya ketika $t$ adalah mean. Root mean-square error, RMSE, adalah akar kuadrat dari MSE.

3. Menggunakan hasil dari nomor 2, berpendapat bahwa deviasi standar nilai minimum RMSE dan nilai minimum ini terjadi hanya ketika t adalah mean. No 2 dan 3 menunjukkan bahwa rata-rata adalah ukuran alami pusat justru ketika varians dan standar deviasi yang digunakan sebagai ukuran penyebaran.

Ingat juga bahwa kita bisa memikirkan distribusi frekuensi relatif sebagai distribusi probabilitas dari variabel acak $\mathrm{X}$ yang memberikan tanda kelas yang berisi nilai yang dipilih secara acak dari kumpulan data. Dengan penafsiran ini, MSE (t) adalah momen kedua dari X tentang t: $\operatorname{MSE}(\mathrm{t})=\mathrm{E}[(\mathrm{X}-\mathrm{t}) 2]$. [4]

\section{HASIL DAN PEMBAHASAN}

Pada bab ini dibahas mengenai implementasi dan pengujian dari jaringan saraf tiruan dengan metode backpropagation, dimulai dari menjelaskan pengujian (Matlab), pemrograman jaringan saraf tiruan (Backpropagation), langkah pengolahan data dengan Matlab dan pelatihan jaringan saraf tiruan.

\subsection{Pengujian Sistem}

Pengujian jaringan saraf tiruan metode backpropagation untuk prediksi penyakit asma dilakukan untuk melihat apakah sistem jaringan saraf ini sudah sesuai dengan kondisi sebenarnya atau tidak. Pengujian jaringan saraf tiruan ini dibagi menjadi beberapa tahap yaitu:

\subsubsection{Tahap Inisialisasi}

Pada tahap ini sistem jaringan saraf diberikan masukan berupa nilai parameter inisialisasi yang terdiri dari :

1 Jumlah sel lapisan masukan terdiri dari 18 simpul input

2 Jumlah sel lapisan tersembunyi dicari berdasarkan percobaan (trial and error) dengan cara mengubah konstanta belajar dan lapisan tersembunyi secara terus menerus sampai diperoleh konfigurasi terbaik yaitu jumlah epoch yang terkecil. Pada sistem prediksi penyakit asma ini diperoleh konfigurasi lapisan tersembunyi adalah 10 simpul.

3 Jumlah lapisan keluaran terdiri dari 4 simpul yaitu Asma akut persisten ringan, asma akut persisten sedang, asma akut persisten berat dan asma akut mengancam jiwa. 
4 Learning rate $(\alpha)=0.5$

5 Maksimal error $=0.001$

6 Maksimal epoch $=5000$

7 Fungsi Aktivasi $=$ Logsig.

\subsubsection{Tahap Pelatihan}

Pada tahap ini sistem jaringan saraf diberikan 20 data sampel penilaian penyakit asma untuk dilatihkan sebagai proses pembelajaran. Untuk mendapatkan nilai keluaran, yang pertama harus dilakukan adalah menentukan matriks masukan dan matriks target.

Selanjutnya menentukan formula dari jaringan saraf tiruan dari feedforward dengan cara mengatur fungsi aktivasi antara masukan lapisan tersembunyi dengan menggunakan logsig(sigmoid biner), fungsi aktivasi dari lapisan tersembunyi ke keluaran menggunakan fungsi aktivasi logsig (sigmoid biner) dan fungsi pelatihan jaringan menggunakan fungsi traingd. Kemudian dilakukan uji coba dengan MATLAB dalam bentuk:

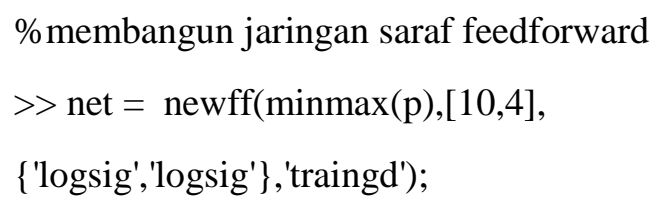

Untuk melihat bobot dan bias Input Ke Hidden Layer dan dari Hidden Layer ke Input Layer dengan menggunakan jaringan yang telah di buat. Adapun perintah yang digunakan di dalam MATLAB adalah:

$>$ net.IW $\{1,1\}$;

Melihat Bias Input Ke Hidden Layer

$>$ net.b $\{1\}$;

Perintah di atas untuk melihat bias input ke hidden layer.

Melihat Bobot Input Ke Output Layer

$>$ net.LW $\{2,1\}$

Perintah di atas untuk melihat bobot input ke output layer.

Melihat Bias Output

$>$ net.b $\{2\}$;

Perintah di atas untuk melihat bias output

Selanjutnya untuk mlihat Hasil Jaringan Saraf Tiruan Pada Iterasi - 1

$>\mathrm{a}=\operatorname{sim}($ net, $\mathrm{p}$ )

> [a,Pf,Af,e,Perf]=sim(net,p,[],[],t)

Dengan perintah di atas didapatkan output aktual iterasi pertama.

Kemudian menentukan jumlah maksimum epochs sangat berpengaruh terhadap kerja pada pelatihan. Nilai epochs pada penelitian ini adalah 5.000 yang kemudian dimasukkan ke dalam MATLAB dengan bentuk:

$$
\begin{aligned}
& \text { \%menentukan maksimum epochs } \\
& \text { > net.trainParam.epochs }=5000 ;
\end{aligned}
$$


Menetukan nilai target error yang menjadi nilai ukur untuk pemberhentian, proses pelatihan akan berhenti jika telah memenuhi target error yaitu 0.001, di dalam MATLAB akan diinputkan berupa:

$$
\begin{aligned}
& \text { \%set target error } \\
& \text { > net.trainParam.goal=0.001; }
\end{aligned}
$$

Menentukan nilai leraning rate agar proses dapat menjadi lebih cepat. $\alpha=$ Learning rate yaitu parameter untuk mengontrol perubahan bobot selama pelatihan. Semakin besar learning rate, maka jaringan syaraf tiruan akan semakin cepat belajar tetapi hasilnya kurang akurat. Semakin kecil learning rate, maka jaringan syaraf tiruan akan semakin lambat belajar tetapi hasilnya lebih akurat. di dalam MATLAB akan dimasukkan dengan bentuk:

$$
\begin{aligned}
& \text { \%set learning rate } \\
& \text { > net.trainParam.lr=0.5; }
\end{aligned}
$$

Selanjutnya adalah melakukan pelatihan backpropagation dan mensimulasikan hasil dari pelatihan, pada tahap ini dilakukan perintah utntuk melakukan pelatihan backpropagation dan perintah untuk mensimulasikan hasil pelatihan di dalam MATLAB adalah:

$$
\begin{aligned}
& \text { \%melakukan pelatihan dan simulasi } \\
& \text { > net=train(net,p,t); \%melakukan } \\
& \text { pelatihan terhadap input dan target } \\
& \text { >> net=sim(net,p); \%melakukan simulasi }
\end{aligned}
$$

Adapun hasil pelatihan yang dilakukan dengan jaringan saraf tiruan adalah:

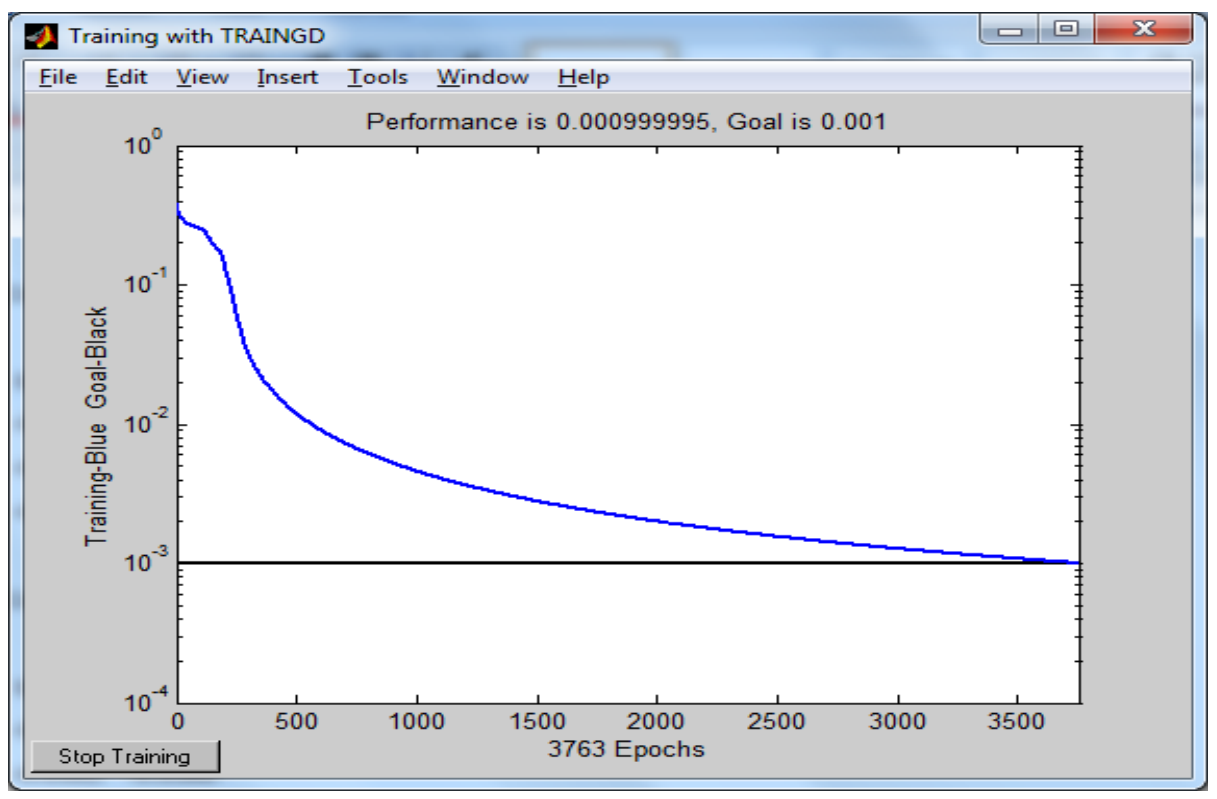

Gambar 3. Hasil pengujian Data Pelatihan dengan 3763 iterasi 
Citec Journal, Vol. 2, No. 1, November 2014 - Januari 2015

ISSN: 2354-5771

Dengan actual output sebagai berikut:

$\mathrm{a}=$

Columns 1 through 9

$\begin{array}{lllllllll}0.0006 & 0.0198 & 0.0006 & 0.0198 & 0.9709 & 0.0267 & 0.0198 & 0.0267 & 0.0198 \\ 0.0290 & 0.9655 & 0.0290 & 0.9655 & 0.0181 & 0.0242 & 0.9655 & 0.0242 & 0.9655 \\ 0.9469 & 0.0252 & 0.9469 & 0.0252 & 0.0302 & 0.0388 & 0.0252 & 0.0388 & 0.0252 \\ 0.0439 & 0.0203 & 0.0439 & 0.0203 & 0.0274 & 0.9522 & 0.0203 & 0.9522 & 0.0203\end{array}$

Columns 10 through 18

$\begin{array}{lllllllll}0.9709 & 0.0267 & 0.0006 & 0.0267 & 0.9709 & 0.0006 & 0.0198 & 0.0267 & 0.0198 \\ 0.0181 & 0.0242 & 0.0290 & 0.0242 & 0.0181 & 0.0290 & 0.9655 & 0.0242 & 0.9655 \\ 0.0302 & 0.0388 & 0.9469 & 0.0388 & 0.0302 & 0.9469 & 0.0252 & 0.0388 & 0.0252 \\ 0.0274 & 0.9522 & 0.0439 & 0.9522 & 0.0274 & 0.0439 & 0.0203 & 0.9522 & 0.0203\end{array}$

Columns 19 through 20

$\begin{array}{ll}0.9709 & 0.0267 \\ 0.0181 & 0.0242 \\ 0.0302 & 0.0388 \\ 0.0274 & 0.9522\end{array}$

Pada pelatihan yang dilakukan dengan MATLAB didapat hasil yang dapat dilihat pada tabel 3 dan tabel 4 di bawah. Pada proses pelatihan jaringan saraf tiruan aini akan berhenti jika iterasi telah sampai pada batas maksimum yaitu 5.000 iterasi, atau pelatihan akan berhenti jika MSE (Mean Square Error) telah berada dibawah target error, disini diketahui target errornya sebesar 0.001. Dengan pelatihan di atas dapat dilihat output yang sesuai dengan target. Di mana untuk nilai output actual diambil yang bernilai 1. Adapun parameter penilaian output actual dengan fungsi aktivasi : $\mathrm{Y}=\left\{\begin{array}{l}0, \text { jika } y<0.5 \\ 1, \text { jika } y \geq 0.5\end{array}\right.$ untuk melihat hasil pelatihan yang dilakukan oleh jaringan saraf tiruan dengan target yang telah ditentukan dapat dilihat pada tabel 3 sebagai berikut:

Tabel 3. Pengujian Data Pelatihan Untuk Arsitektur 18-10-4

\begin{tabular}{|c|c|c|c|c|c|c|c|c|c|c|c|c|c|c|c|c|c|c|c|c|c|}
\hline No & $\mathrm{Xl}$ & $\mathrm{X} \mathbf{2}$ & \begin{tabular}{l|l}
$\mathrm{X} 3$ \\
\end{tabular} & $\mathrm{X} 4$ & $\mathrm{X} 5$ & $\mathrm{X} 6$ & $\mathrm{X} 7$ & $\mathrm{X} 8$ & $\mathrm{X} 9$ & $\mathrm{X} 10$ & $\mathrm{X} 11$ & $\mathrm{X} 12$ & $\mathrm{X} 13$ & $\mathrm{X} 14$ & $\mathrm{X} 15$ & $\mathrm{X} 16$ & $\mathrm{X} 17$ & $\mathrm{X} 18$ & KS & HPU & KJST \\
\hline 1 & 0 & 0 & 0 & 0 & 1 & 1 & 1 & 1 & 0 & 0 & 0 & 0 & 0 & 0 & 0 & 0 & 0 & 0 & 0010 & 0010 & cocol \\
\hline 2 & 0 & 0 & 0 & 0 & 0 & 0 & 0 & 0 & 1 & 1 & 1 & 1 & 0 & 0 & 0 & 0 & 0 & 0 & 0100 & 0100 & cocok \\
\hline 3 & 0 & 0 & 0 & 0 & 1 & 1 & 1 & 1 & 0 & 0 & 0 & 0 & 0 & 0 & 0 & 0 & 0 & 0 & 0010 & 0010 & cocok \\
\hline 4 & 0 & 0 & 0 & 0 & 0 & 0 & 0 & 0 & 1 & 1 & 1 & 1 & 0 & 0 & 0 & 0 & 0 & 0 & 0100 & 0100 & cocok \\
\hline 5 & 0 & 0 & 0 & 0 & 0 & 0 & 0 & 0 & 0 & 0 & 0 & 0 & 1 & 1 & 1 & 1 & 1 & 1 & 1000 & 1000 & cocok \\
\hline 6 & 1 & 1 & 1 & 1 & 0 & 0 & 0 & 0 & 0 & 0 & 0 & 0 & 0 & 0 & 0 & 0 & 0 & 0 & 0001 & 0001 & cocok \\
\hline 7 & 0 & 0 & 0 & 0 & 0 & 0 & 0 & 0 & 1 & 1 & 1 & 1 & 0 & 0 & 0 & 0 & 0 & 0 & 0100 & 0100 & cocok \\
\hline 8 & 1 & 1 & 1 & 1 & 0 & 0 & 0 & 0 & 0 & 0 & 0 & 0 & 0 & 0 & 0 & 0 & 0 & 0 & 0001 & 0001 & cocok \\
\hline 9 & 0 & 0 & 0 & 0 & 0 & 0 & 0 & 0 & 1 & 1 & 1 & 1 & 0 & 0 & 0 & 0 & 0 & 0 & 0100 & 0100 & cocok \\
\hline 10 & 0 & 0 & 0 & 0 & 0 & 0 & 0 & 0 & 0 & 0 & 0 & 0 & 1 & 1 & 1 & 1 & 1 & 1 & 1000 & 1000 & cocok \\
\hline 11 & 1 & 1 & 1 & 1 & 0 & 0 & 0 & 0 & 0 & 0 & 0 & 0 & 0 & 0 & 0 & 0 & 0 & 0 & 0001 & 0001 & cocol \\
\hline 12 & 0 & 0 & 0 & 0 & 1 & 1 & 1 & 1 & 0 & 0 & 0 & 0 & 0 & 0 & 0 & 0 & 0 & 0 & 0010 & 0010 & cocok \\
\hline 13 & 1 & 1 & 1 & 1 & 0 & 0 & 0 & 0 & 0 & 0 & 0 & 0 & 0 & 0 & 0 & 0 & 0 & 0 & 0001 & 0001 & cocok \\
\hline 14 & 0 & 0 & 0 & 0 & 0 & 0 & 0 & 0 & 0 & 0 & 0 & 0 & 1 & 1 & 1 & 1 & 1 & 1 & 1000 & 1000 & cocok \\
\hline 15 & 0 & 0 & 0 & 0 & 1 & 1 & 1 & 1 & 0 & 0 & 0 & 0 & 0 & 0 & 0 & 0 & 0 & 0 & 0010 & 0010 & cocol \\
\hline 16 & 0 & 0 & 0 & 0 & 0 & 0 & 0 & 0 & 1 & 1 & 1 & 1 & 0 & 0 & 0 & 0 & 0 & 0 & 0100 & 0100 & cocok \\
\hline 17 & 1 & 1 & 1 & 1 & 0 & 0 & 0 & 0 & 0 & 0 & 0 & 0 & 0 & 0 & 0 & 0 & 0 & 0 & 0001 & 0001 & cocok \\
\hline 18 & 0 & 0 & 0 & 0 & 0 & 0 & 0 & 0 & 1 & 1 & 1 & 1 & 0 & 0 & 0 & 0 & 0 & 0 & 0100 & 0100 & cocok \\
\hline 19 & 0 & 0 & 0 & 0 & 0 & 0 & 0 & 0 & 0 & 0 & 0 & 0 & 1 & 1 & 1 & 1 & 1 & 1 & 1000 & 1000 & cocol \\
\hline 20 & 1 & 1 & 1 & 1 & 0 & 0 & 0 & 0 & 0 & 0 & 0 & 0 & 0 & 0 & 0 & 0 & 0 & 0 & 0001 & 0001 & cocok \\
\hline
\end{tabular}


Kemudian diuji lagi dengan data baru dengan 10 sampel data dengan output actual sebagai berikut:

$\mathrm{a}=$

Columns 1 through 9

$\begin{array}{lllllllll}0.0140 & 0.0399 & 0.9549 & 0.9549 & 0.0123 & 0.0399 & 0.0140 & 0.0123 & 0.9549 \\ 0.0134 & 0.0301 & 0.0416 & 0.0416 & 0.9646 & 0.0301 & 0.0134 & 0.9646 & 0.0416 \\ 0.9570 & 0.0433 & 0.0098 & 0.0098 & 0.0258 & 0.0433 & 0.9570 & 0.0258 & 0.0098 \\ 0.0283 & 0.9635 & 0.0377 & 0.0377 & 0.0130 & 0.9635 & 0.0283 & 0.0130 & 0.0377\end{array}$

Column 10

0.0123

0.9646

0.0258

0.0130

Untuk melihat hasil pengujian 10 data baru yang dilakukan oleh jaringan saraf tiruan dengan target yang telah ditentukan dapat dilihat pada tabel 4 sebagai berikut:

Tabel 4. Pengujian Data Baru Untuk Arsitektur 18-10-4

\begin{tabular}{|c|c|c|c|c|c|c|c|c|c|c|c|c|c|c|c|c|c|c|c|c|c|}
\hline $\mathbf{N}_{0}$ & $\mathbf{X 1}$ & $\mathbf{X} 2$ & $\mathbf{X} 3$ & $\mathbf{X} 4$ & $\mathbf{X} 5$ & $\mathbf{X} 6$ & $\mathbf{X} 7$ & $\mathbf{X} 8$ & $\mathbf{X} 9$ & $\mathbf{X 1 0}$ & $\mathbf{X 1 1}$ & $\mathbf{X 1 2}$ & $\mathbf{X 1 3}$ & $\mathbf{X 1 4}$ & $\mathbf{X 1 5}$ & $\mathbf{X 1 6}$ & $\mathbf{X 1 7}$ & $\mathbf{X 1 8}$ & KS & HPU & KJST \\
\hline $\mathbf{1}$ & 0 & 0 & 0 & 0 & 1 & 1 & 1 & 1 & 0 & 0 & 0 & 0 & 0 & 0 & 0 & 0 & 0 & 0 & 0010 & 0010 & Cocok \\
\hline $\mathbf{2}$ & 1 & 1 & 1 & 1 & 0 & 0 & 0 & 0 & 0 & 0 & 0 & 0 & 0 & 0 & 0 & 0 & 0 & 0 & 0001 & 0001 & Cocok \\
\hline $\mathbf{3}$ & 0 & 0 & 0 & 0 & 0 & 0 & 0 & 0 & 0 & 0 & 0 & 0 & 1 & 1 & 1 & 1 & 1 & 1 & 1000 & 1000 & Cocok \\
\hline $\mathbf{4}$ & 0 & 0 & 0 & 0 & 0 & 0 & 0 & 0 & 0 & 0 & 0 & 0 & 1 & 1 & 1 & 1 & 1 & 1 & 1000 & 1000 & Cocok \\
\hline $\mathbf{5}$ & 0 & 0 & 0 & 0 & 0 & 0 & 0 & 0 & 1 & 1 & 1 & 1 & 0 & 0 & 0 & 0 & 0 & 0 & 0100 & 0100 & Cocok \\
\hline $\mathbf{6}$ & 1 & 1 & 1 & 1 & 0 & 0 & 0 & 0 & 0 & 0 & 0 & 0 & 0 & 0 & 0 & 0 & 0 & 0 & 0001 & 0001 & Cocok \\
\hline $\mathbf{7}$ & 0 & 0 & 0 & 0 & 1 & 1 & 1 & 1 & 0 & 0 & 0 & 0 & 0 & 0 & 0 & 0 & 0 & 0 & 0010 & 0010 & Cocok \\
\hline $\mathbf{8}$ & 0 & 0 & 0 & 0 & 0 & 0 & 0 & 0 & 1 & 1 & 1 & 1 & 0 & 0 & 0 & 0 & 0 & 0 & 0100 & 0100 & Cocok \\
\hline $\mathbf{9}$ & 0 & 0 & 0 & 0 & 0 & 0 & 0 & 0 & 0 & 0 & 0 & 0 & 1 & 1 & 1 & 1 & 1 & 1 & 1000 & 1000 & Cocok \\
\hline $\mathbf{1 0}$ & 0 & 0 & 0 & 0 & 0 & 0 & 0 & 0 & 1 & 1 & 1 & 1 & 0 & 0 & 0 & 0 & 0 & 0 & 0100 & 0100 & Cocok \\
\hline
\end{tabular}

Keterangan :

KS = Kondisi Sebenarnya

HPU = Hasil Pengujian

KJST $=$ Ketepatan Jaringan Saraf Tiruan

Kemudian Untuk memperoleh konfigurasi terbaik maka dilakukan beberapa pengujian dengan berbagai arsitektur. Untuk menguji akurasi pelatihan jaringan saraf tiruan digunakan beberapa model arsitektur jaringan saraf tiruan yaitu 18-8-4, 18-12-4, 18-14-4, 18-16-4, dan 1818-4. Berikut ini merupakan tabel hasil pelatihan jaringan saraf tiruan dari 5 arsitektur tersebut dengan perubahan nilai hidden layer.

Tabel 5. Tabel Perubahan Nilai Uji Coba Data Pelatihan Dengan Perubahan Nilai Hidden Layer

\begin{tabular}{|l|l|l|l|l|}
\hline Hidden & Epochs & Learning rate & Error & MSE \\
\hline 8 & 4707 & 0.5 & 0.001 & 0.00100139 \\
\hline 12 & 4184 & 0.5 & 0.001 & 0.000999781 \\
\hline 14 & 3634 & 0.5 & 0.001 & 0.000999811 \\
\hline 16 & 2711 & 0.5 & 0.001 & 0.000999646 \\
\hline 18 & 1599 & 0.5 & 0.001 & 0.000999951 \\
\hline
\end{tabular}

Dari beberapa hasil ujicoba yang telah dilakukan dapat diambil kesimpulan bahwa proses prediksi penyakit asma menggunakan algoritma backpropagation dengan berbagai arsitektur. Suatu arsitektur mempunyai kinerja sangat bagus jika nilai MSE berada di bawah nilai error yaitu 
0.001 Dari beberapa uji coba yang dilakukan diperoleh parameter yaitu learning rate sebesar 0.5 , toleransi error 0.001, maksimal epoch 4707 dan hidden layer 8 dengan nilai MSE 0.00100139. Parameter tersebut dipilih menjadi parameter terbaik karena menghasilkan jumlah iterasi yang memiliki nilai akurasi MSE yang cukup baik, karena nilai MSE paling kecil dari arsitektur yang lain serta nilai MSE dibawah dari nilai error yang ditentukan.

\section{KESIMPULAN}

Berdasarkan hasil dari analisis pada tahap pelatihan dan tahap pengujian prediksi penyakit asma ini didapat beberapa kesimpulan, antara lain:

1 Metode backpropagation dapat digunakan untuk menyelesaikan masalah prediksi penyakit asma dengan menggunakan empat pola tampilan output yang terdiri dari Asma Akut Persisten Ringan, Asma Akut Persisten Sedang, Asma Akut Persisten Berat, Asma Akut Mengancam Jiwa.

2 Pengujian jaringan saraf dilakukan dengan memasukkan data pelatihan dan pengujian dan diperoleh hasil pengujian sampai $100 \%$ sesuai dengan target yang di inginkan

3 Pelatihan terhadap jaringan saraf dengan 18 sel lapisan masukan dilakukan pada 20 data sampel penyakit asma yang terdiri dari 6 data dengan pola keluaran asma akut persisten ringan, 4 data dengan pola keluaran asma akut persisten sedang, 6 data dengan pola keluaran asma akut persisten berat, 4 data dengan pola keluaran asma akut mengancam jiwa.

4 Konfigurasi jaringan terbaik yang diperoleh melalui percobaan (trial and error) adalah dengan 8 sel lapisan tersembunyi dan konstanta belajar 0.001 dengan fungsi aktivasi yang digunakan adalah fungsi sigmoid biner (logsig).

\section{SARAN}

Berdasarkan pengujian yang telah dilakukan pada jaringan saraf tiruan yang telah dibuat, tentunya masih ada kekurangan dan kelemahan yang terjadi sehingga perlu dikembangkan lagi agar kinerjanya lebih baik. Adapun saran untuk pengambangan penelitian ini adalah:

1 Untuk pengembangan penelitian yang lebih baik lagi dapat membuat suatu perangkat lunak untuk mengimplementasikan jaringan saraf tiruan dengan metode backpropagation untuk memprediksi penyakit asma agar lebih mudah dipahami oleh masyarakat awam.

2 Setelah dilakukan pelatihan dan pengujian untuk memprediksi penyakit asma menggunakan jaringan saraf tiruan metode backpropagation, disarankan agar diadakan penelitian lebih lanjut dengan menggunakan metode-metode lainnya agar dapat di ambil kesimpulan metode apa yang paling baik dalam kasus memprediksi penyakit asma.

\section{UCAPAN TERIMA KASIH}

Penulis mengucapkan terima kasih kepada keluarga dan institusi yang telah memberi dukungan financial terhadap penelitian ini. 


\section{DAFTAR PUSTAKA}

[1] Indah, M. N., Ismiarti, R., 2010, Implementasi Jaringan Saraf Tiruan dalam Aplikasi Identifikasi Huruf Vokal Berdasarkan Pola Gerak Bibir, Jurnal Petir, Vol. 3, No. 1. Hal 5967

[2] Pradasari, N. I., et.al, 2013, Jaringan Syaraf Tiruan untuk Memprediksi Penyakit Saluran Pernafasan dengan Metode Backpropagation, Jurnal Coding, Vol 1, No 1.

[3] Kiki, Kusumadewi, S., 2004, Analisis Jaringan Saraf Tiruan dengan Metode Backpropagation untuk Mendeteksi Gangguan Psikologi,Jurnal Media Informatika, Vol 2, No 2, hal 1-11.

[4] Mean, Variance, and Mean Square Error, http://www.fmi.uni-sofia.bg/vesta/virtual_labs/ freq/freq5.html, diakses tanggal 08 Februari 2014. 